\title{
O VELHO IMPÉRIO DE CARLOS V (*)
}

Há quatrocentos e cinqüenta anos atrás nascia Carlos, filho de Felipe o Formoso, Arquiduque de Áustria e de Dona Joana a Louca, princesa: castelhana, neto de D. Fernando II de Aragão e de Dona Isabel I de Castela, pela linha materna, e do Imperador Maximiliano de Augsburgo e do Dona Maria de Borgonha, pela linha paterna. Duque de Luxemburgo em suミ meninice, príncipe de Castela em sua adolescência, rei da Espanha em sua primeira juventude e imperador da Alemanha as cumprir a bela idsde de vinte anos. Enfim, Carlos I da Espanha e V da Alemanha. Alguns supernacionalistas apaixonados de última moda batem-se por que se quebre o hábito de falar Carlos V; que só se diga Carlos I, pois o que interessa aos espanhóis é que era o rei da Espanha e não o imperador da Alemanha Mas a verdade é que a sugestão impeperial e c eufemismo fizeram triunfar o primeiro título, já desde os seus cronistas contemporâneos, como o "Caballero Cesáreo" ou Pedro Mexia (1492-1551), Luis de Avila ỳ Zúniga (m. por volta de 1573) e Francisco López de Gomara (1511-1557), até os historiadores hodierncs, os quais não hesitam em denominá-lo simplesmente $\mathrm{C} z$ rlos V. Fiquem os nacionalismos para detalhes de maior envergadura. Por outro lado, os acontecimentos históricos sucedem-se sem que nos demcs conta, com peculiaridades que $c$ tempo não apaga mas confirma. O neto dos Reis Católicos, declarado primeiro soberano da Espanha pelai morte do avô viúvo, Dom Fernando, e pela continuada incapacidade mental de sua mãe, também viúva, dona Joana, e que não obteria o título de imperador da Alemanha senão três anos depois, inaugurava, graças à sua ascendência austríaca, mais direta, a primeira dinastia estrangeira em tôdas as Espanhas. E estrangeiro chegava à península sia marítima, a 17 de setembro de 1517; nascera em Gante. Acompanhava-o um séquito de que sobressaiam os nomes de Juan de Sauvage, Guilleume de Croy, senhor de Chièvres, o senhor de Beure e o de Lency, entre outros cavalheircs e cortesãos de Flandres; falava só o francês e o flamengo. Sua educação fôra dirigida por sua tia Margarida, viúva do príncipe Dom João, primogênito dos Reis Católicos, filh 三 de Maximiliano, e que exercera a regência em Flandres, e a tutela de Carlos, que aos 6 anos ficara órfão de pai e sem proteção de sua infeliz mãe, dona Joana, cuja incapacidade,

\footnotetext{
(*). - Tradução do texto espanhol pela Licenciada Lucy Ribeiro de Moura.
} 
real ou "oficial", durou até o fim de seus dias. Dona Joana de Castela, rainhel da Espanha, morreu a 11 de abril de 1555, cu seja, com setenta e sete anos de idade; seu filho Carlos iria falecer com cinqüenta e oito. A loucura de dona Joana, se realmente existiu, prolengcu estrarhamente a vida obscura daquela nuluher; as crônicas da côrte de Flandres, onde vivera como espôsa de Felipe o Formoso, testernunham qus, apesar daqueles seus gestos chocantes, que tanto alarmaram dona Isabel de Castela, foi uma princesa culta, eloqüente e com nítidos rasgìs de mansidão, como indiscuivelmente revelou, mesmo quando, em sua correspondência com a rainha mãe, referia-se aos rumores sôbre a sua condição mental.

Como dizímos, Carlos chegcu inteiramente estrangeiro; alheio, mesmo, aos negócios que the deparava sua alta missão na Espanha. Volvendo à sua educação, fator muito considerado pêta os efeitos da crítica do seu reinado, o verdadeiro inspirador na eleição dos preceptores, inclusive da tutora, $\mathrm{fci}$ seu avô Maximiliano; e. entre os eleitos estava, além do eminente nobre flemengo Guilaume de Croy, Florizoo de Urrecht, o teólcgo Adriano, depois papa Adriano VI, que contava entre os seus colaboradores, $\mathrm{ccm}$ o humanista espanhol Luiz Vives (1492-1540). As primeiras lições de história miristradas $\varepsilon 0$ espírito juvenil de Carlos referiam-se à casa de Borgonha, desde o fundador da segunda linha, Jcão o Bom, até o último, conde Carlos o Temerário, famosc em seu tempo, eximio antecedente.do mais legítimo cavalheiro renascentista, espade! audaciosa, ávido de glória e dado às artes e à literatur?, impenitente guerreiro contra Luiz XI, até terminar com o seu condado e com a sua vida na batalha de Nancy. Já desde esta primeira educação na côrte flamenga, teve Carlos que ir experimentanto cs influxos opcstos de nobres e preceptores, políticas latentes na crientação dos estudes, nos conselhos e nas insinuações confortadoras. O senhor de Chièvres representavar o indômito nacionalismo que fervia na ncbreza dos Países-Baixos; e por outro lado a família, personificada em dona Margarida, velava pela raíz austriaca e pelo ramo bcrgonhês, com sonhos de mais amplos horizontes. Causa perplexidade, entretanto, que os doutos professôres que o tiveram a seu cuidade, não the facilitassem a eduçção humaniste, ao extremo $d$ e descuidarem o ensino do latim, deficiência que Carlos teve que lamentar em sua carreira $d_{e}$ soberano. Certo é que algo ganhou nesse vazio de aprendizagem humanista, compensado com os exercícios físicos, a equitação, a caçミı e cs torneics, programa predileto do senhor de Chièvres, e que a Carlcs thes serviu, pelo menos, para preservar-se, no futuro, com uma resistência maior de sua saúde, com um não vacilar em pôr-se à frente de suas tropes nes batalhas com que ilustrou o seu reinado. 0 estrangeirismo de Carios tem sido tese preferida nos modernos tempos, pera explicar-nos sua "espanholização" e a "hispanidade" de suas glórias, assunto um tanto perigoso, sobretudo quando o fo- 
caliza Menéndez Pidel, ao que nos referiremos com certa insistência e a propósito da iđéia imperial de Carlos V. Daqui, talvez, - haver-nos habituado a ver o primeiro rei da dinastia austríaca na Esparha, ora com seu manto de imperador alemão, sentado ao trono dos Reis Católicos, ora com sua figura eqüestre, vestido de brilhante armadura, $\mathrm{ccm}$ a lança $\epsilon \mathrm{m}$ riste, voltando as costas a Castela e dirigindo-se para as ribeires do Elba, como na contenda de Mühlberg contra os luteranos. Esta efígie nô-la legou Ticiano, no célebre retrato que se conserva no museu do Prado de Madrí. Este rei espanhol sempre nos pareceu mais ccmo Carlos V que como Carlos 1 .

O escritcr, já um pouco caduco, embora dos posteriores à gereção de 98, Ramón Pérez de Ayala, ao evocar o imperador em uma ligeira crônica pericdística, reccrre às suas reminiscências de estudante e à escondida simpatia que, co aprender a história da Espanha, sentia-se por essa figura, envolvidal nas perturbaçōes da Reforma na Europa, e que teve "certas complacências com os protestantes" (1). E é verdade; a sombra de Carlos V atraía-nos sem que. soubéssemos por quê, talvez por seu "cosmopclitismo", por zquêles seus antecedentes gernânicos e borgcriheses, em contraste com a rígida e tenebrosa senda que seguiria seu filho. Felipe II, e com al decadência persistente do resto da dinastia, que se consome em complicações domésticas, palacianas, inúteis, entre sotainas e orações, devaneios sensuais, mórbidos e uma política exterior em espantoso declive...

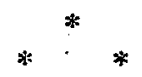

O reinado de Carlos $V$ está cheio de contradições, afirma o filólogo e historiador espanhol Remón Menéndez Pidal (2), e eis aqui a primeira premissa de nossa afirmaçãa de "velho império de Carlos V", velho em seu verdadeiro sentido, de vestuto e ana. crônico, não sòmente quando observado històricamente à luz de nossa filosofia política ctuail, mas analisado em sua própria época. Senil em seu germe, sobressaindo-se sust decrepitude no marco dos grances acontecimentos europeus do século XVI; e espantosamente contraditório ao final, quando a Espanha se impunhe no Novo Mundo pelo descobrimento é pela colonização. O sentido

(1). - O sennor Érez de Ayala, autor de uma novela anti-jesuítica A.M. G.D. (1910), agora, err sua cronica aludida, rompe lanças a favor das "Forças eficazes dos filhos de Santo Ináclo de Loiola", que salvara não sei quantas cuisas, e se retifica, dizendo que "Felipe II 6 um dos protagonistas maiores mais patéticos da Idade Moderna", quando havia abrigado antes "gérias dúvifas e receios con respeito a tảo austero monarca". A trajetória dêste escritor espanhol, de filiação liberal e em seu tempo republicano militante. e que depois de um desterro voluntário regressou à pátria, parese terminar naquela cauda de peixe da "Arte Poética de Horácio: "Desinit in piscem". (Veja-se o "ABC" de Madri, de 10 de setembro de 1948 , seu artigo "Nos arqulvos da memória"). (2), - Crf. pás. 15, do rolune 172 da Col. Austral, Espasa Calpe de Euenos Aires, 2.3 edicăo, aquêle que inclui uma conferencia dè Menéndez Pidal, publicada em Havana em 1938 e que dá 0 t́tulo a esse volume Idels Imporial de Carioe $\mathbf{r}$. 
do império europeu-cmericano, de que fala Pidal, inato na aspiração política de Carlos $V$, não tem base alguma e reduz-se a um efeito retórico com que pretende culminar uma exposição de circunstâncias, ante um aữitório propício. Mas voltaremos a êste ponto.

O tema do último imperador espanhol, como o de outras insignes figuras da História espanhola, continua ainda sem um ccmpleto e firme estudo biográfico e crítico. Neste caso como nos outros, infelizmente, faz-se preciso recomendar is trabalhos de penas estrangeiras. mais que das peras pátrias, especialmente ao tratarse de grandes personalid: des da vida política espanhola. E' preciso buscar fora o objetivismc. O catcilicismo nacional e sua conseqüente ortodoxia, com os psrfis severos dêsse individualismo espanhol que engana com sua pretendida indisciplina histórica, porque é no individualismo que se refugia o orgulho; e a cegal negativa de reconhecer cs etros do passado não permiterr, nem ao cronista, nem ao historiador nacionais, iluminar a atmosfera tradicionál. Pelo que se vê, nestes dias a atrofiz da visão histórica revela-se bestante considerável, sempre em nome do mito individualista.

O que sucede com o reinado de Carlos $V$, é que o seu ascendimento coincide com uma era de profundas e transcendentais transições na Espanha e na Europa, como foi a iniciação do século XVI. Se o soberano sucessor daquela genial rainha que foi Isabel a Católica, sem menoscabo de sua "espanholização", não houvesse perdido sua "europeizaçâc" primáris è de promessas fecundas, tampouco teria preparado a idiosincrasia de Felipe II, que esgotou uma virtuzididade que a Espanha teria aplicado a emprêsas mais conscientes com o ritmo da História, mais proveitosás para a própria existência nacionel. A herança dos Auustrias, recolheram-na os Bourbons, ccm a fatalidade de que tźmbém êstes trcuxeram à Espanha, para fazê-los reviver, os vestígios de uma indole politica. ainda assim provecta na França, em que pese aos alctrmas que produziram cs "afrancesados" com sua onda de modernismo.

O próprio interêsse constantemente despertado na Alemanha e na Bélgica pela perscnalidade de Carles $V$, ao lado da apagada atenção dos eruditos hispánicos, é mais uma amostra de que o tratar o assunte força os espanhóis a uma revisão de valores históricos, cazalogados como em um' arquivo, e que o remcvê-los com uma nova critica supóe ferir frraigados prejuizos nacionais. $O$ curioso é que as mesmas contradiçōes advertidas no reinado repetem-se, também, em juizcs recentes com que certos publicistas espanhóis desejam encarar destacados episódios daquele momento histórico.

Quando Carlos V entrou na: Espanha, encontrou-se com as: Côrtes que intervinham nos atos do soberano. As de Valladolid, no ano seguinte zo de sua chegada, muitc a contragosto declararam-lhe fidelidade. Dis dona Joane continuava sendo para os pro- 
curadores representantes a soberana de Castela, embora com a reserva de sue incapacidade física. Com esta condição implicits, embora só tivesse uma conseqüência nominal para a fórmula nas providências reais, reconheceram-no a Cárlos I. Em boa lei jurídica castelhana, o rei Carlos não foi mais que o regente da Espanha; transmitiram-lhe cs poderes do Cardeal Cisneros, pelo ano de 1555, em que faleceu sua mãe. Ano da pəz de Augsburgo, que admitiu legalmente $o$ Protestantismo, ano $\mathrm{em}$ que Carlos não sabia quê fazer com o seu Impéric nem com a gôta qua lhe mineva a vida, ano em que preparava sueı abdicação e seu retiro ao mosteiro de Iuste, para alí morrer no seio da ordem dos Jerônimos. "Ordem bucólica, folgazã, de uma religicsidade sem irquietações, preocupada com o rigor da liturgia e com a suntuosidade do culto... Religiosos medievais, qusiquer coisa de inatual na vida do século XVI hispânico. Tôdas as formas da religiosidade são ativas, militantes, quando Carlos de Europa entra no remanso jerônimo. Tão pouco, pois, em capítulo para êle primordial, o da salvação de sua alma, soube inctrporar-se a uma fôrça espiritual representativa dミ Espanha de seu tempi": (3).

De Valladolid seguiu Carlos seu itinerário para ser reconhecido como o legítimo soberano de tôda a Espanha e receber o juramento de Aragão*e de Catalunha. Estando em Barcelona, soube da morte do seu avô Maximiliéno e da decisão dos eleitores de nomeá-lo sucessor. Solicitou subsídics, para a viagem à Alemanha, nas Côrtes de Santiago de Galiza, onde lhos negaram, e transladou a $r \equiv u n i a ̃ c$ dos procuradores a La Coruñ $\equiv$, conseguindo, por suborno, uma maioria favcrável. Confiou o govêrno da Espanha a Adriano, já cardeal, e saiu da penínsuia. Muitas das queizas e reclamaçốes das Côrtes ficaram arbitràriamente desatendiđas pelo monarca, estranho àquela máquinz: administrativa de funcionamento liberal, egrégia tradição espanhola. Em sua ausência ocorre c levantamento dos Comuneiros, ou guerra das Comunidades de Castela, movimento popular, defensor da liberdade comunal ameaçada pelas tendências absolutistas de Carlos. Os comuneiros acolheram-se à legalidade da rainha mãe, que residia em Tordesilhas, e que ofereceu sua autorização ręl para que a junta revolucionária decretasse suas ordens, em seu nome. O levante fracassou. As traições e as deserções da nobreza, a principio unida à causa, desorganizaram a cempanha, tendo os imperiais vencido na batalha que se deu perto de Villalar (Valladolid), sacrificando ós três cabecilhes: Juan de Padilha, Juan Bravo e Francisco Maldonado. A sanção históriçı tem sido unânime; o episódio dos Comuneiros foi um transe sem fortuna para as comunidades representativas e para aquêle poder que refreava, em nome das vontades pcpulares, $o$ ar-

(3). - A expanholizacão de Carlos $v$, por Aurelio Viñas. Publicacão do Centro de Estudos romanicos. Iena und Leipzig, Yerlar von Wilhelm Gronau. 1038. Pag. 18-10. 
bítrio dos monarcas. Hoje quer-se profañar, destruindo o caráter daquela nobre jornada, o espírito que a promoveu.

E' uma supresa decepcionante, êste critério do autorizado historiador Antonio Ballesteros y Berreta (4): "O levantamento comuneiro foi interpretado diversamente, segundo a mente dos historiadcres de escola. Em sua gênese $e$ desenvclvimento teve um sentido anti-cesarista. Desembaracadas as razões altgadas então, observamos que ccultavam a verd:deira intenção. Apareciam unidos nobreza e municípios, elementos antagónicos durante a Idade Média, mas que agora se aliavam contra o inimigo comum: o absolutismo do rei. Com o título de liberdade e privilégios comunzis encobriam situaçôes de privilégio. Era o feudalismo abatido por Fernando e Isabel, a nobreza levantina, que Cisneros dominara, alçando-se de novo com a oportunidade da ausência do soberano. As Comunidades representavam o velhc, o caduco, o medieval, já inservivel para resolver os grandes problemas politices do mundo; e deante déles Carlos V era o progresso, a teoria nova, a solução decisiva e salvadora que daria eficácia e rapidez à cbra de govêrno" (5). Este critério é de uma flagrante contradição. Se a nobrezs aderiu acs comuneiros, com o egoismo de defender situaçōes pessoais, ou acusavam o absolutismo do rei, ou lançavam mão dêsse procedimento para defrontar-se com os privilégics da nobreza flamenga $q u_{E}$ rodeava $o r \in i$. Se bem depressa desertaram da causa foi porque, ou não viram o êxito seguro dos seus propósitos ccultos, ou porque thes era mais prático passar-se ao $\mathrm{c}$ m mpo absolutista e, nos dois casos, céda qual defendia os próprios interêsses de linhagem. Que o triunfo de Carlos representava uma grande e inovadcra idéia de govérno, quebranđo o "feudalismo" senhorial como se nada houvesse conseguido a rainha Isabel $€ m$ sua obra de unidade nacicnal, é uma afirmação gratuits. Em ccmpensação, sim, - triunfo da monarquia carolina selou, desgraçıdamente, o destino político da Espanha durante o poder dos sucessores de Carlos, prolcngando-se até nossos dias com os desastres exteriores por interêsses dinásticos e a cruenta história das guerras civis, provocadas pela obtusa intransigência dos teis, com a colaboração das arraigadas instituiçōes que medraram à scmbra dos tronos (6).

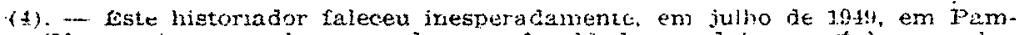
plona (Navarra), e em pleno uso de suas facudades produtoras. te bem conheciro o mérito de suá História da depanha em lí volumes. Investigáar metódrco e serio, seus úitimos trabalios, que proviveimente se publicaráa como obra posturaia, refereru-se a duas eminentes figuras espanholas, "Afonso $\mathrm{X}$, o Sabjo" : "Fernandu. o Santo".

(5). - Cfr. o volume 67i da Col. Austral de Espasa-Calpe de Buenos Aires: Tyrara imperiais de Antonio Ballesteros y Berreta. Eidiçá 194. Pags. $48+49$.

(i). - Dss: juizo contrário a sisnificacão jiberal da fuera das Comunidacies, compartiháa, pelo visto, o senhor Gremorio Marañón que, na tibuna de voraninfo da Lnversiade de Earcelona. no ano passado, com afetaços de revuluncionitio intérprete das efcmérides históricas de sua pátria. erremeteu contri "a atitude apologetica da historiografia liberal do século XID" que atribuiu has commeiros a defesa da iberdade de Castela ameaçda por um monarca ibsolutista." Wara o senhor Marañin, a ideologia era a do César, Carlos $v$. me representava una idéia universal, "ao lado dos ressaibos fendalizantes dos 
Quê rzzōes expōem êstes comentaristas modernos sôbre a outra efervescência popular, coeva da guerra das Comunidades, que foi a guerra das Germânias đe Valência, em. 1522, verdadeira luta de classes, animada pelo ódio ̀̀ aristocracia? Os ventos que sopravam pela Europa eram outros que os que podiam auxiliar o verdadeiro "feudalismo" ancestral dos reis, que agora se chamava absolutismo، Fêz bsm Carlos $\mathrm{V}$ em afogar, pela fôrça, aquêles sintomas de emancipação popular, e em conter o que houvesse de "europeização" da península, com tôdas as suas conseqüências, começando pelo fruto que ia dar a expansão da Refcrma. Assims a Espanha ficou ali, sem evançat um passo mais, onde a deixou Isabel a Católica.

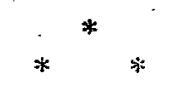

Falemos da segunda premissa, que põe em relêvo a evidente caducidade, $\in \mathrm{m}$ sua época, do que representava a idéia imperial $\mathrm{d}_{e}$ Carlos V. Remón Menéndez Pidel não está de acôrdo com Karl - Brandi a êste respeito. Antonio Ballesteros disse também sua palavra nesse assunto, $\mathrm{ccm}$ grande reverência para com o mestre, mas sem dissimular uma agudeza histórica mais profunda. Menéndez Pidal fez-ncs olvidar, nesta questão, seu dominio de historiador, para fazer-nos lembrar simplesmente o filólogo e o crítico literário, como veremos. Em sintese, não se tratou de discutir os bens e os males que causou a política de Carlos V, ùnicamente de disputer the a autenticidade de seu gênio político imperialista. Se foi seu ou se o tomou emprestado. Claro que assim expcsto o tema, não parece que vai proporcionar, em princípio, a conclusão que mais nos interessa: Mas, nel própria matéria discutida vamos encontrar-nos com a outra fôrça do silogismo, que nos oferecerá, por dedução, o result: do que anelamos:.

Karl Brandi estudou, durante muitos anos, com severa reflexão de mentalidade germânica e abundância de selecionada e valiosa documentação e um sentido de pura objetividade histórica, a personalidede de Carlcs $V$, seu ambiente e as silhuetas dos que modelarem e fundiram suas inspiraçõ ss imperialistas. Revela-nos que a personagem Mercurino Gattinara fôra o chanceler mais irrfluente na atividade de Carlos V. Não se realizaram, até esta data, trabalhos mais completos que os $\mathrm{d}$ e Brandi, secundàdo, em parte, pelo Doutor Peter Rassow. Assim ratificamos nossa opiniãc já consignada sôbre a superior ciêricia interpretativa dos eruditos estrangeiros em muitos momentos da Histórial da Espanha. O fato também se registra nas análises das eminências literárias espanholas.

anvalheiros e burguesea castelhanos". Contra essa superstiçāo histórica, um comentarists catalao replicou-lhe, pitorescamente, dizendo-ihe que, deciajarmente, "a decadencia da Hispanha no seculo XVII explica-se pelo triunfo de Carlos V". 
Esta sugestāo da vida e do pensamento da Espanha são atraentes e fascinadori $\mathrm{b}$, precisamente para cs que näo são espanhóis.

Desde 1926, vem Karl Brandi publicendo monografias, memórias, autobicgrafias, notas, informes, estudes sôbre Carlos V, nos volumes e cadernos de Nachrichten von der Gesellschaft des Wisenschaften de Gotinga, editados alguns em Berlim e em Cottigen e outros artigos no Preussische Jahrbicher e no Ibero Amerikarisches Archiv. Dentre os estudos seleciona Pidal o Der Kaiser und sein Kansler de Karl Brandi, publicação no N. G. W. Z. de 1933 e o do doutor Peter Rassow, Die Kaiser-Idee Karls V. dargestellt an der Politik der Jahre 1528-1540, embora faça também referências às Memórias de Gattinara, publicadas por Brandi. $O$ Chanceler Gattinara era oriundo do Piemonte, de sólida cultura e claríssima inteligência; instalara-se em Flandres em 1518, atraíndo a ztenção de Margarida da Áustria, que o recomendou para o conselho privado de seu sobrinho Carlos. Destacou-se na côrte por sua assiduidade ao trabalho, por seus indiscutiveis serviços e, até a sua morte, em 1530, esteve pertc do soberano. Para Karl Brandi êste conselheiro foi o antífice espiritual do Imperador; com o que está de acôrdo Ballesteros, e com o quß não concorda TMenéndez Pidal. Não vamos seguir a êste, em sua dialética histórica dos "quatro momentos" (7), porque não vale a pena; é bastante qu? se abarquem umas quantas linhas gerais. Mas, antes, nã ¿ quisér£mos omitir un esbôço particular sôbre Carlcs V, o Imperador coroado duas vézes - uma, em Aquisgrán (Aix-la Chapelle), no ano seguinte ao que fôra eleito e outra, oito anos depois, desta vez como rei da Lomberdia e Imperador dos Romanos, tendo ido expressamente à Itália para ser ungido pelo próprio Papa Clemente VII, aquêle que fôra castigado pelo Condestável de Bourbon, a serviço de Carlos, no saque de Roma de 1526. Digamcs algo sôbre as qualidedes intelectuais do Imperador. Sôbre o talento natural de Carlos V conformam-se os historiadoras com. pinceladas confusas em sua semeihança. Segundo Pidal, "Era ainda um jovem indeciso e apoucado, de gesto absorto e boquiaberto (um cemponês, em Calatayud, acabava de dizer-lhe, ao ver-lihe caída a mandíbula: "Majestade, fech insolentes"). Este jovem, de mentalidade atrasada, dominado pelos flamengos que roubavam o erário de Castela... êste jovem; que nos conselhos de govêrno da Espznha nada resolvia sem que . The sussurrassism acs ouvidos, de joêlhos, ante o público, Chièvres ou Gattinara... etc. etc. (8). Para Ballęsteros, nos primeircs momentos de sua permanência na Espanha: "Em sua mente fervism idéias de govêrno que bem depressa aflorariam" (9). Alude, em outra passagem, a um autor que considera exageradamente "que Carlos

(T) - Cr. ob. eit., Idéla Imperial de carlos $v$.

(8) - Ob. cit., pás. 17

(a). - Ob. ctt., vag: 48. 
não amadureceu sua inteligência tardia até 1530" (10). Aurelio Viñas, outro historiador muito apreciável, diz, em seu opúsculo publicado em Iena, já amotado, que era "de altura média, pálido, com a bôca aberta, a manđíbula inferior saliente, rasgos de característica herança borgonhesa. Todos concordam em que é um ta: citurno com arranques súbitos de energia. Murmura-se que the dão síncopes e que estas são da caráter epilético. Expressava-se com dificuldade e parece certo que sua inteligência era mediana, retardada". Viñas não faz thais que resumir os retratos que circulavam sôbra Carlos V.

Ballesteros tenta descobrir a evolução intelectual do Imperador por um procedimențo psico-fisionomista, através da cronologia de suas ef́́gies. E examina a iconogrefia carolina de várias épocas, desde os 23 anos, data de uma miniatura que adorna um precioso documento arquivado em Valladolid, até que a "gôta o aflija", seguramente em um retrato que se guarda no Museu de Munique. Não deixa de referir-se às duas pinturas do Museu de Madrí, uma retratando o Imperador em pé, de támanho natural, t o mais celebrado, o eqüestre, montado em cavalo castanho, a galope e empunhando a lança, ambos do Ticietno. Quantas vêzes contemplávamos êste documento pictórico no Prado, a impressão, com tocios os respeitos devidos ao César e ao retratista, era desagradável. O cavaleiro não tem arrogância alguma nem vivacidade no rosto, e parece um homem embrulh sdo em armadura e forçado a uma exibição deante de uma objetiva fotográfica. Trata-se de um momento preciso na vida de Cerlos V, a batalha de Muhlberg, a nada mais. A fina agudeza do historiador Ballesteros, baseandose em retratos do Imperador, não nos leva muito longe, e for aquêles que eu conheço, não desperta entusiasmo algum al potência intelectual que se possa revelar nos traços reproduzidos.

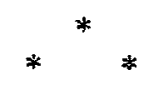

Falar da idéia imperial de Carlos $\mathrm{V}$ como de um parto mental e político do neto dos Reis Católicos, no século XVI, já é acusar um acontecimento em contraste com as tendências de govêtno na. Europa daqueles tempos. $E$ discutir o problema como o expõe $P \mathbf{P}-$ dal para opor-se a Brandi, que póe em relêvo o chanceler Gattinara, como o mentor de Carlos na execução do seu projeto, é desviarse do assunto no que pede ter de fundamental. "A idéia imperial não foi inventada por Carlos nem pelo seu chanceler - diz o filó logo espanhol -; é uma. noção velhíssima, que êles não fizeram senão captar e adaptar às circunstâncias". Circunstâncias trgañdcras, como a própria história demonstrou. Continua dizendo Pidal:

(10). - Ob. cit., pas. 32. 
“O Império era a forma mais perfeita da sociedade humana; por isso Deus perpetuava sôbre a terra o Império, desce os temposmais remotos del História, transferindo-o đe Babilônia a Macedônia, a Cartago e a Roma. O império romano exercera essa potestade suprema, extensa e compieta, durante seis séculos, scbretudo desde Augusto até Justiniano. Logo, embora muito deficiente e apoucedo, renova-se no império carolínio dos séculos IX e X. Depois, mais apoucado ainda, sucede c império romano-germânico" (11). Em virtude, pois, desta fórmula histórica de sucessão degenerada dos impérios, não nos cabe mais, se thes dames razão ao insigne erudito expanhol, que prognosticar ao novo império carolino uma débil e efêmera natureza. Assim tra. Aurélio Viñàs, entretanto, crê que a única coisa efetiva e nova era um império espanhol, fundado em uma monarquia mais ou menos universal com $o$ descobrimento do Novo Mundo. "O sacro Império romano-germânico - diz êle - não tem de romano senão o nome, rpesar de suas pretensōes da continuador do precedente. Entidade fundzda no sistena medieval de harmcnia das du:s autoridacies supremas, $\mathrm{Pa}$ pa e Imperador. Império bicéfalo, com um chefe espiritual, vigário de Jesús Cristo e o imperador, sucessor de Augusto. Tém ambos missão compartida, que isoladamente não pcdem levar a cabọ. Propósito supernacions pa. Nem por sua estrutura, nem por seu espírito, era fácil fundir ambes os impérios"... E muito menos podia o imperader Carlos conseguir. em sua época, tal unidade imperial, com os cismas católicos que vinha arrastindo a Igreja, e com o grande cisma religioso da Reforma! Que fôsse a forma mais perfeita de organizaçāo humana na remota Antiguidade, não quer dizer que o continuasse sendo no transcurso dos séculos e muito menos no século XVI. A fôrça m: terial que Augusto impôs já não tinha sentido no progresso das fórças de moral política que se opunham séculos depois. Em 1844 já Emerson đefinia o império, em seu The Young American, como "um imenso egctismo." E nisto ficaram tôdas as tentativas imperialistas da hcra atuad, de tão trágica experiência, em loucuras de ambição pessoa!.

A reivindicação da originalidade imperialista de Carlos, baseiaa Menéndez Pidal em discursos e declarações que, segundo êle, em nada se deveram ao ditado de Gattinara. E' um serviço patriótico êsse que presta o historiador, exalçando figuras meritórias na teclogia, na literatura e no humanismo, quando näo ao próprio Dom Carlos, com "sentimentes herdacios de Isabel a Católica, madurecidos em Worms, nem presença de Lutero e declaradıs públicamente..." E Fidal faz desfilar deante de. nós ai Dom Pedro Ruiz ce la Mota bispo de Bed:jiz, em sua diclaração ante as Côrtes de L $=$ Coruña de 1520, porta-voz do novo Imperador; a Alfonso de.

(11). - Gb. ctt. de Pidal, págs. 13-14. 
Valdés, irmão do ainda mais distinto Juan de Valdés, falecido cêrca de 1532, secretário de Carlos, que redigiu a resposta imperial ao breve $d_{\mathrm{e}}$ Clemente VII sôbre o Saque de Roma, de 1526. Por certo que êste Valdés, humanista erasmiano, demonstrava uma evidente simpatia pela Reforma. A Antônio de Guavara (1480?-1545), de Santander, muito conhscido então na Europa, franciscano, inquisidor em Valência, bispo em 1528, autor de um livro de intenção pedagógica, em forma novelesca, Relógio de Príncipes, de indigesta leitura para nós, $m \equiv s$ com seu mérito estilístico para o historiador literário, e ao que Pidal considera como autor anônimo do discurso pronunciado pelo Imperador em Madrí, em 1528, em que anunciava sua viagem à Itália, cnde serial coroado pelo Papa e geriria a convocatória de um Concílio geral que decidisse sôbre a heresia de Lutero. Gattinara, a juízo de Menéndez Pidal, não colaboral nestes atcs do Imprador. Mas tão grande é o significado de que fôssem eruditos espanhóis os encarregados de dar forma literária às declarações imperiais? Tem razão Ballestercs quando diz: "negar que o trato assíduo do chanceler ccm o Imperador coädjuvesse sua formação espiritual seria qualificar a Carlos $V$ de mente obtusa e impermeávei” (12). Há mais: entre Gattinara, seu indiscutivel conselheiro, por uma parte, e por outra parte a intervenção de seus secretárics e crcnistas espanhóis, o relêvo pessoal de Carlos V cibscurece-se bastante. A acre contestação de Valdés co Papa, em nome de Carlos, é a de um simpatizante com os luteranos, a de um futuro protsstante. $\mathbf{E}$ a intervenção de Gattinara, com seu incontestável influxo, no episódio do Saque de Roma, examina-o mais profundamene Ballestercs, ressaltando a condição de gibelino do chanceler, de "trajetórisı ideológica dantesca e humanística" e "os Papas eram tão guelfos como seus antecessores, ccntemporâness de Frederico I Staufen". O amálgama de católicos e protestantes na luta contra o Papa, ñquela ccasião, já foi suficientemente explicade, pois Clemente inspirava-se em interêsses pròpriamente partidários, fazendo-se inimigo de uns e de outros. A Pidal sugestionour-o a idéia de qua Carlos defendia a Igrejer universal, até mesmo sôbre o personalismo dos Pontífices.

Carics V, não obstante, ganhou para o julgamento da posteridade certas páginas de alto acento espanhol e de espírito conciliador e benevolente. No último sentido, sua atitude após a derrota de Frsncisco I, em Pavie, atitude que foi tão mal correspondida pelo ambicioso soberano da França:

Como rei da Espanha e com sua investidura de imperador, os histcriadores hispânicos, sem exceção, gabam-lhe, merecidamente, aquela sua nobre errogância espanhola, que marca uma data imcrtedóura para a universalidade da língua de sua pátria hispânica. Aó regressar de sua campanha em Tunis, contra Barb:rcxa, 
en uma memorável entrevista diplomática na sala dos "pasamenti" do Vaticano, à que comparecia o embaixador francês, 0 bispo de Macon, a 17 de abril de 1536, quando Carlos V denunciava em idioma espanhol as intrigas francesas, o bispo galo interveit, não compreendendo bem as expressões do Imperador. Carlos repiicou-1he: "Senhor bispo, entenda-me se quiser e não espere de mim outras palavras que as de minha língua espanhola, que afinal é táo nobre, que merece ser conhecida e entendida de tôda a gente cristã". Este sim, que era um programa de aspirações universais, o que formulou Añtônio de Nebrija, como anota Aurélio Viñas. Parece que êsse discurso de Carlos, no Vaticano, não chegou a ser publicado por razóes de "alta política", mas divulgou-se profusamente em cópias manuscritas. "Teve um eco enorme na Espanha e no Novo Mundo, nas ithas do Mar Caribe, no Perú, no México, provando já a forte unidade linguistica do império ultramarino que nascia então" (13).

Há um iastante em que Pidal e Ballesteros coincidem, embora não por caminhos idênticos, em sua divergência com o historiađor Karl Brandi: Quando da admiração dêste por Lutero, a quem eleva a um plano que não aceitam os ortodoxos espanhóis. "A atitude de Lutero leva em si uma grandeza fascinadora" observa Brandi e exalta vivarnente a obra luterana na formação do Estado alemão. Carlos demonstrou, em certo momento, o desêjo de uma conciliação cam os protestantes, não se pode negá-lo. Nesta: atitude, os cronistas espanhôis atuais se apressam a fazer constar o fervor católico. "Carlos era a antítese de Lutero. Enquanto o César se desvela duramte tôda a sua existência de soberano para lograr a unidade de seu Império alemāo, Lutero desagrega-o. Sua doutrina dissociadora rompe a sagrada unidade da Igreja, fraciona as crenças e negal a autoridade do Papa, cúspide unitária da Catolicidade" (14). De bem pouco the serviu a Carlos êsse esfôrço, ante a implacável serenidade dos acontecimentos, aos que era impossível desvirtuar com obstáculos imperialistas. Pelo tratado de Passau (1552) e pala $\mathrm{Paz}$ de Augsburgo (1555) teve Carlos que inclinarse à tealidade dos fatos consumados, ao triunfo do protestantismo como doutrina legal. Carlos não pôde conseguir que seu irmão Fernado renunciasse aos seus direitos em favor de seu filho $\mathrm{Fe}$ lipe; o príncipe da Alemanha, tão cátólico como protestante, náo seguiu o conselho do Imperador. Carlos, ao retirar-se pare Iuste, com Gattinara ou sem Gattinara, com tôda a obra de seus colaboradores espanhóis, sentiu o profundo desencanto de seus mais fervorosós desejos. Não the inspirava esperança alguma no porvir sua decantada idéia imperial.

(13). - Aurélio Viñas em seu citado opúscula.

(14). - Ballesterns. Ob. cit., pkg. 64. 
A unidade européia, não se pođia consegui-la recuperando a política de Augusto, nem aquelai monarquia universal que, diz $\mathrm{Pi}$ dal, era a ambição de Gattinara, nem a "universitas christiana" que, a afirma, era a sã intenção de Carlos, expressada pelo bispo Motai Tudo adoecia do mesmo mal anacrônico. Mas, no que sobretudo se mostra confuso IMenéndez Pidal, é quando, ao final de sua dissertação sôbre as idéias imperiais de Carlos $V$, quer mostrar que Carlos V "quis europeizar a América, hispanizando-g também, para incorporá-la à cultura ocidental". E coloca Hernán Cortés ao lado de Mota, de Valdés e de Guevaré E nos recorda as Leis das Indias, que em sua substância prístina estavam já no testemunho de Isabel a Católica. Não, Carlos V, entregue ao seu Império romano e germânico, às suás intimas inquietações de dogma católico e às suas tarefas belicosas na Europa, não compreendeu o que para um Império autentico supunham os novos horizontes que brilhavam do outro lado do Atlântico. Não podia encrustar-se esta visão na caducidade de sua idéia imperial européia. Volto a dar a palavra final a Aurélio Viñas, supondo que se atrevesse agora a confirmá-las, pois desđe 1936 até esta datai têm-se modificado muitas mentalidades espanholas. "Juristas, humanistas, religiosos e povo viam com clareza a idéial de um Império ocidental que não era uma quimera como a que acariciava a mente de Carlos $\mathrm{V}$ - mente de cavalheiro e governante de passados tempos - mas outro que prolongava a Europa..." O Império espanhol, fundado na América, arruinou-se pelas velhas manias imperiais que herdou Fellipe II, que acabou de destroçar o não menos velho absolutismo bourbon. Império pela cultura, pela língua, por um novo espírito, isto não podiam entendê-lo os Césares". O império de Carlos V nasceu com o germe de sua rápida decompcsição, ao buscar o que a História já enterrara.

LUIS AMADOR SÁNCHEZ 